\title{
Multi-criteria decision analysis and spatial statistic: an approach to determining human vulnerability to vector transmission of Trypanosoma cruzi
}

\author{
Diego Montenegro ${ }^{1,2} /{ }^{+}$, Ana Paula da Cunha ${ }^{3}$, Simone Ladeia-Andrade ${ }^{1}$, \\ Mauricio Vera ${ }^{4}$, Marcel Pedroso ${ }^{3}$, Angela Junqueira ${ }^{1}$ \\ ${ }^{1}$ Fundação Oswaldo Cruz-Fiocruz, Instituto Oswaldo Cruz, Laboratório de Doenças Parasitárias, Rio de Janeiro, RJ, Brasil \\ ${ }^{2}$ Fundación Chilloa, Santa Marta, Colombia \\ ${ }^{3}$ Fundação Oswaldo Cruz-Fiocruz, Instituto de Comunicação e Informação Científica e Tecnologia em Saúde, Rio de Janeiro, RJ, Brasil \\ ${ }^{4}$ Ministerio de Salud y de la Protección Social, Bogotá, Colombia
}

BACKGROUND Chagas disease (CD), caused by the protozoan Trypanosoma cruzi, is a neglected human disease. It is endemic to the Americas and is estimated to have an economic impact, including lost productivity and disability, of 7 billion dollars per year on average.

OBJECTIVES To assess vulnerability to vector-borne transmission of $T$. cruzi in domiciliary environments within an area undergoing domiciliary vector interruption of T. cruzi in Colombia.

METHODS Multi-criteria decision analysis [preference ranking method for enrichment evaluation (PROMETHEE) and geometrical analysis for interactive assistance (GAIA) methods] and spatial statistics were performed on data from a socio-environmental questionnaire and an entomological survey. In the construction of multi-criteria descriptors, decision-making processes and indicators of five determinants of the CD vector pathway were summarily defined, including: (1) house indicator (HI); (2) triatominae indicator (TI); (3) host/reservoir indicator (Ho/RoI); (4) ecotope indicator (EI); and (5) socio-cultural indicator (S-CI).

FINDINGS Determination of vulnerability to CD is mostly influenced by TI, with $44.96 \%$ of the total weight in the model, while the lowest contribution was from S-CI, with 7.15\%. The five indicators comprise 17 indices, and include 78 of the original 104 priority criteria and variables. The PROMETHEE and GAIA methods proved very efficient for prioritisation and quantitative categorisation of socio-environmental determinants and for better determining which criteria should be considered for interrupting the man- $T$. cruzi-vector relationship in endemic areas of the Americas. Through the analysis of spatial autocorrelation it is clear that there is a spatial dependence in establishing categories of vulnerability, therefore, the effect of neighbors' setting (border areas) on local values should be incorporated into disease management for establishing programs of surveillance and control of CD via vector.

CONCLUSIONS The study model proposed here is flexible and can be adapted to various eco-epidemiological profiles and is suitable for focusing anti-T. cruzi serological surveillance programs in vulnerable human populations.

Key words: vulnerability - Chagas disease - multi-criteria decision analysis - spatial statistic - PROMETHEE method - GAIA method

Chagas disease (CD), produced by the protozoan Trypanosoma (Schizotrypanum) cruzi (Chagas 1909), is a neglected human disease. It is endemic to the Americas, but cases have been reported from almost every continent of the world (WHO 2015). Approximately 7 million people are infected in Latin America, a region where it causes more than 7,000 deaths per year (WHO 2015). It has been estimated that the economic impact of $\mathrm{CD}$, including lost productivity and disability, averages 7 billion dollars per year (Lee et al. 2013).

Since the discovery of vector transmission of CD by Carlos Chagas (Chagas 1909), which is known as the classical pathway of Chagas pathology, it continues to be considered a zoonosis with multifactorial determinants: different species of triatomine vectors and mammalian reservoirs,

doi: 10.1590/0074-02760160523

Financial support: CNPq

+ Corresponding author: dc.montenegro85@gmail.com

Received 5 December 2016

Accepted 22 April 2017 infrastructural conditions of housing favorable to the domiciliation of vectors, lack of specific information by those living in areas at risk, low access to health services, lack of vaccines, drugs effective only in acute infections, etc. (Chagas 1909, Forattini 1980, Montenegro et al. 2016). The problem of the disease extends beyond the health sector, and requires holistic policies that integrate the search for cost-effective measures; the performance of sustainable surveillance; and the promotion, prevention and control of the disease, including comprehensive care for individual cases (i.e., diagnosis, treatment and rehabilitation).

Several proposals to address different biological and socio-environmental determinants for human infection with $T$. cruzi by triatomine vectors are available (Vinhaes et al. 2014, Tah et al. 2015, WHO 2015).

The presence, density and degree of synanthropy exhibited by different populations of triatomines in artificial environments and anthropic areas determine the level of danger for the occurrence of cases of vector transmitted CD (Silveira et al. 1984). However, this is not all that is required for the transmission of the parasite from insects to humans, since certain conditions of 
the landscape are needed at the local level (indoors and peridomiciliar areas), and the knowledge and practices of people exposed to danger can influence their ability to confront the threat of transmission (Tah et al. 2015). Therefore, to better understand the human-parasite-vector relationship and the degree of social vulnerability to infection, disease or death by T. cruzi, all elements must be integrated for a better understanding of the relevant biological, ecological and social determinants.

Over the years, various models have been developed for identifying and determining vulnerability and risk of transmission of the vector of $T$. cruzi, integrating biological (Rabinovich et al. 1979, Silveira et al. 1984, Catalá et al. 1997) and biological with socio-environmental determinants (Guhl 2000, Silveira 2003). However, there is little evidence of the actual implementation of these models, for exemplo in Guhl et al. (2005).

A detailed analysis found that the risk models currently in use (Guhl 2000, Silveira 2003) cannot be applied to areas below the scale of municipalities, such as rural areas and villages. They prioritize the inclusion of an anti-T. cruzi serological indicator for human populations in their mathematical algorithms, making them very expensive and not easily applied in routine monitoring programs of $\mathrm{CD}$ endemic countries.

Therefore, given the current international effort to interrupt domiciled vectors of T. cruzi (WHO 2015) and to strengthen programs of surveillance and vector control in endemic countries, new strategies and methodologies have become necessary so as to integrate the greatest possible number of determinants of vectors of $C D$ in decision-making, management and resource allocation from local (home) to national (country) levels.

In this sense, the present paper uses multi-criteria decision analysis (MDA) to assess vulnerability to vectorborne transmission of T. cruzi in domiciliary environments within an area undergoing domiciliary vector interruption of $T$. cruzi in Colombia. The proposed model aims to be viable in terms of cost-benefit. It is applied from the residential level to the national level and is considered sufficiently flexible to be adapted to the reality of CD endemic areas with different epidemiological patterns.

A MDA approach allows situational analysis with a multi-criteria perspective, since a given epidemiological problem is influenced by various characteristics or variables referred to, in this manuscript, as criteria.

The MDA approach is being increasingly implemented in the area of public health (de Oliveira et al. 2015) and has even already been applied to CD (Vinhaes et al. 2014).

\section{MATERIALS AND METHODS}

The following phases of MDA were defined: (i) structuring phase; (ii) modeling phase; and (iii) evaluation phase. The objective of the structuring phase is to understand the studied situation. It comprises four stages: (1) definition of the spatial dimension of the question; (2) generation of multi-criteria tree of indicators and description of the dimensions of indicators; and (3) construction of multi-criteria descriptors. The modeling phase mathematically expresses human vulnerability to vector transmission of T. cruzi, and the evaluation phase presents the results of the model.

MDA structuring phase - The spatial dimension in question is defined as the municipality of Támara, located in northwestern Colombia in the department of Casanare $\left(5^{\circ} 49^{\prime} 58.77^{\prime} \mathrm{N}, 72^{\circ} 09^{\prime} 42.05^{\prime \prime} \mathrm{W}\right)$. It encompasses a total area of $1,181.81 \mathrm{~km}^{2}$, of which $1,180.9 \mathrm{~km}^{2}$ are in rural areas containing 50 villages (political divisions) (Fig. 1) (http://www.tamara-casanare.gov.co/informacion_general.shtml). The temperature of the region varies between $12-23^{\circ} \mathrm{C}$ (mean $\left.20^{\circ} \mathrm{C}\right)$.

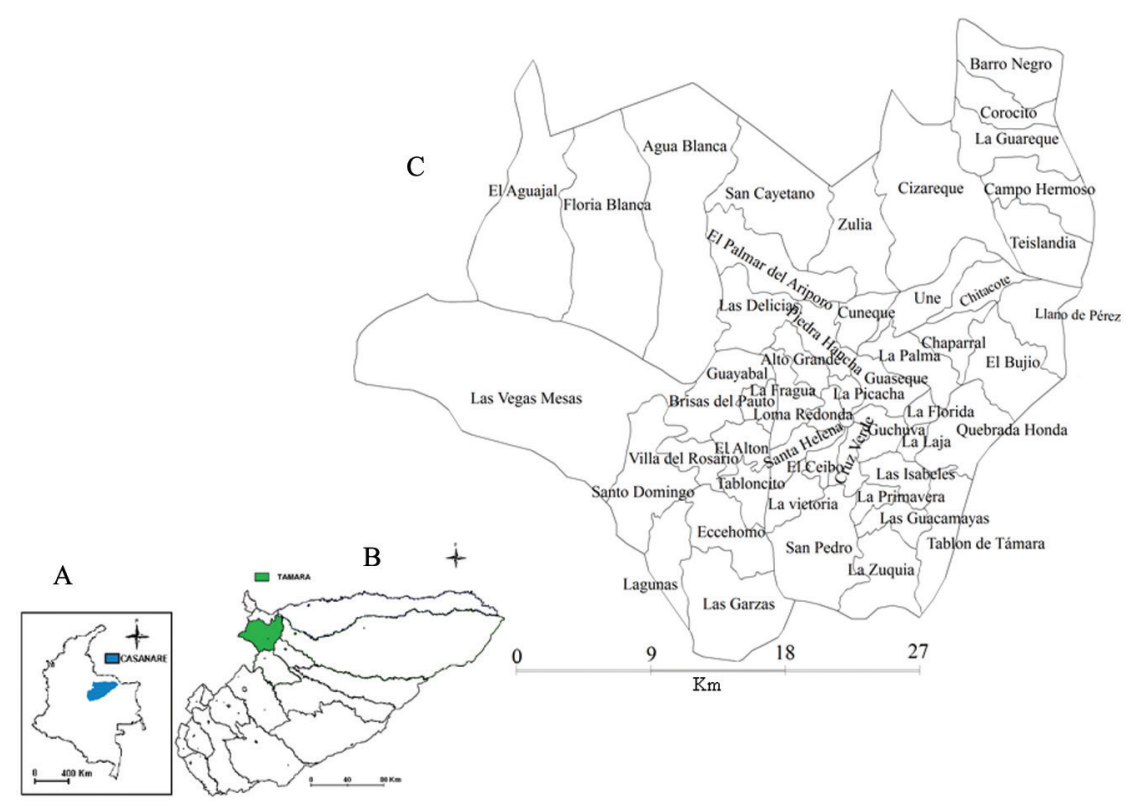

Fig. 1: geographical locations of the department of Casanare (A), the municipality of Támara (B) and the policy division of Támara (C). 
Between 2008-2013, approximately 680 cases of chronic CD were reported in Colombia, plus another 18 acute cases (Vega 2014). Since the first epidemiological reports and studies of CD in Colombia (Guhl et al. 2005), Arauca, Boyacá, Casanare and Santander were recognised as the most epidemiological significant departments (Vega 2014). These departments were subsequently prioritised by the national plan to interrupt the transmission of T. cruzi by the intradomiciliar vector Rhodnius prolixus (OPS 2011). Within the department of Casanare, the municipality of Támara is considered endemic for $\mathrm{CD}$ and was one of three municipalities selected for the implementation of the interruption program (OPS 2011).

A socio-environmental questionnaire and an entomological survey were employed in the municipality (Supplementary data), to evaluate the physical conditions of domicile, the inhabitants' knowledge about CD, the entomological indicators of triatomines, the presence of hosts/reservoirs of T. cruzi and the biotypes of vegetation in the peridomicile area. The techniques and methods used for collecting information were initially presented by Montenegro et al. (2016).

In the multi-criteria tree of indicators and description of the dimensions of indicators, the criteria (variables) were grouped into indicators according to the information reported in Supplementary data, and then included in rates according to the nature of the information. Tree selection follows a logical organisation of criteria and is based on a theoretical framework used by more than 30 previous studies, all of which addressed CD and elements of the transmission cycle of T. cruzi (see in detail, Table I). These studies included protocols for triatomine surveillance, meetings and expert consensuses, as well as articles involving field and laboratory work. They also reflect the contribution of more than 100 experts and more than a century of information from CD research, since the time of discovery of CD to the most recent studies of determinants of the disease (Chagas 1909, Montenegro et al. 2016).

In the construction of multi-criteria descriptors, decision-making processes and indicators of five determinants of the Chagas disease vector pathway were summarily defined, including: (1) house indicator (HI) - an aggregate of different indices regarding the structural conditions of houses; (2) triatominae indicator (TI) - including entomological indices and route of natural infection by T. cruzi; (3) host/reservoir indicator (Ho/RoI) - a collection of indices evaluating associations between domestic and wild animals and CD; (4) ecotope indicator (EI) - including several indicators related to surrounding habitats that provide shelter and favor the establishment of triatomine populations; and (5) socio-cultural indicator (S-CI) - a collection of different variables pertaining to population structure and an overview of community knowledge of CD (Table I).

MDA modeling phase - In this phase of MDA, indicators, indices and criteria based on numerical values were incorporated into the decision-making model by employing peer-to-peer comparison. This comparison method attributes a preferential value in which two in- dices, two indicators or two criteria, are graphically compared to one another, generally using the D-sight program (Hayez et al. 2012). All preferential values are detailed in Table I. Theoretical weights, ranging from 1 to 100 , for the components of the decision-making model were generated using the preference ranking method for enrichment evaluation (PROMETHHE method) through peer-to-peer comparison (Brans \& Mareschal 1994).

It is noteworthy that the PROMETHEE and geometrical analysis for interactive assistance (GAIA) methods were developed in order to help the individual or collective decider. These methods serve to solve problems in selecting or making arrangements of possible alternatives (territories, options, shares), subject to an assessment of various of criteria (variables, qualitative and quantitative indices, indicators, attributes, any criteria with numerical values), which may be in conflict with each other and seek to simultaneously satisfy different views for decision making (Brans \& Mareschal 1994, Mareschal \& de Smet 2009).

The scores for alternatives (villages) were visualised in frequency histograms for the absolute values of vulnerability, with bars being made to reflect the contribution of each index to the total vulnerability value.

The scores were sorted in ascending order and the villages with the three lowest and three highest vulnerability values were included in the cobweb (radar) graph. The GAIA-stick method was used to visualise vulnerability values of each community previously obtained by the PROMETHEE method (Hayez et al. 2009, Mareschal \& de Smet 2009). Visualisation was done at two levels: first, the five indexes were used as statistical vectors, and second, the five indexes were used along with the most relevant vulnerability indicators of the PROMETHEE analysis.

Finally, the resulting scores of the PROMETHEE model were used for spatial statistical analysis. The spatial dependence of vulnerability for each area assessed was analysed using the Moran Local Index - LISA (Anselin 2010), with 9999 permutations, no spatial autocorrelation and considering statistical significance (LISAsig) to be greater than 0.05 . All spatial statistical analyses were performed using the program TerraView (INPE 2010).

MDA evaluation phase - In this phase, the results of the model are presented.

\section{RESULTS}

Multi-criteria modeling found the determination of vulnerability to vector-borne transmission of $T$. cruzi in the endemic area of Colombia to be mostly influenced by TI with $44.96 \%$ of the total weight in the model, while the lowest contribution was from S-CI, with $7.15 \%$. The five indicators are made up of 17 indices, and include 78, of the original 104 priority criteria and variables (Table II).

According to the weight of each indicator, the largest absolute value for the occurrence of cases of CD by vector are the criteria associated with the colonisation of homes by triatomine vectors $R$. prolixus and Panstrongilus geniculatus, natural infection of T. cruzi vectors and the perception of triatomines in the bedroom by the inhabitants (Table II). 
TABLE I

Evaluation and decision tree for the biological and socio-environmental determinants of vulnerability to intradomiciliary vector-borne Trypanosoma cruzi transmission to humans

\begin{tabular}{|c|c|c|c|}
\hline Indices & Criteria & Estimate & Reference \\
\hline \multicolumn{4}{|c|}{ House indicator (HI) } \\
\hline Wall type & $\begin{array}{c}\text { Bahareque, adobe, wood, block or } \\
\text { brick, other, no wall }\end{array}$ & $\begin{array}{l}\text { Percentage } \\
\text { composition of }\end{array}$ & \multirow{5}{*}{$\begin{array}{l}\text { (Rabinovich et al. 1979, } \\
\text { Guhl 2000, Silveira 2003, } \\
\text { Sosa-Jurado et al. 2004, } \\
\text { Montenegro et al. 2016) }\end{array}$} \\
\hline Wall plaster & Partially, Without plaster, total plaster & each material & \\
\hline Roof type & $\begin{array}{c}\text { Thatch, palm tree leaves, clay tile, } \\
\text { zinc, Eternit, etc. }\end{array}$ & & \\
\hline Floor type & Wooden, tiling, uncoated, cement & & \\
\hline Annexes & $\begin{array}{c}\text { Corral: rustic bower, henhouse, stable, } \\
\text { pigsty, barn, kitchen, etc. } \\
\text { Deposits: external areas of leisure } \\
\text { or work, accumulation of firewood, } \\
\text { stones, etc. }\end{array}$ & $\begin{array}{l}\text { Qualitative } \\
\text { variables: } \\
\text { presence } \\
\text { and absence }\end{array}$ & \\
\hline
\end{tabular}

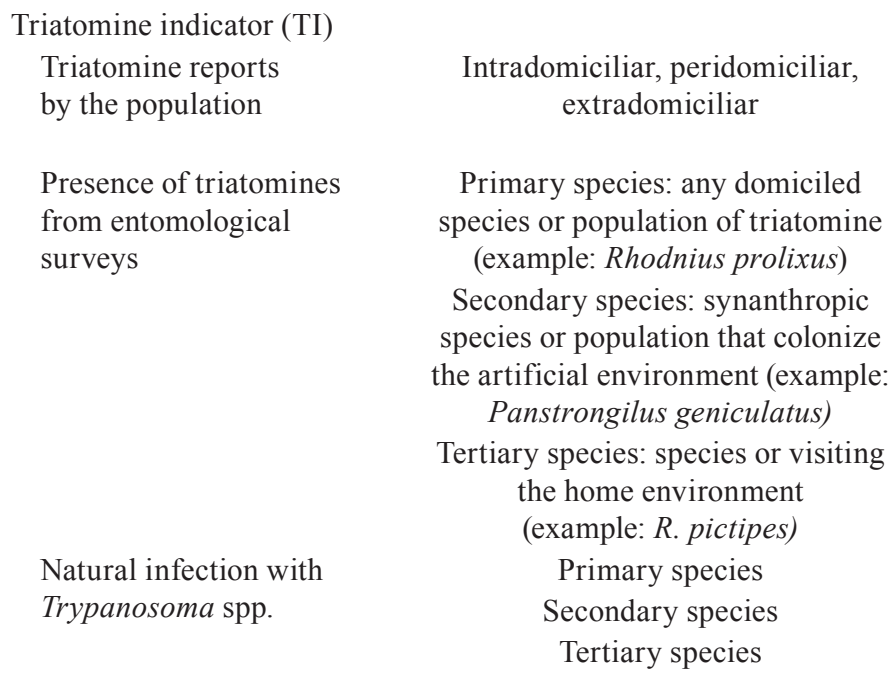

Percentage of homes with triatomine reports

Entomological triatomine indicators: dispersion, colonization and infestation rates
(Silveira et al. 1984, Romaña et al. 1999, MSPS/INS 2011,

Abad-Franch 2016, Montenegro et al. 2016)
Natural infection
percentage with
Trypanosoma spp by species
(Perlowagora-Szumlewicz \& Moreira 1994, Junqueira et al. 2011, MSPS/INS 2011)

\section{Ecotope indicator (EI) Palm tree}

Presence of other ecotopes (dry trees, bromeliads, nesting birds or mammals) Presence of monocultures
Primary species: palm tree presence functioning as habitat for triatomine specialists or habitat for different species of triatomines. Example: Attalea butyracea and Leopoldina piassaba.

Secondary species: does not meet the above criteria but can be infested with triatomines. Example: Elaeis guineesis, Mauritia flexuosa, and other species of Attalea)

Tertiary species: no history of triatomine infestation.

Example: Euterpe olaracea presence
Percentage

of houses with palm tree presence
(Feliciangeli et al. 2007, Noireau et al. 2009, Abad-Franch et al. 2010) 


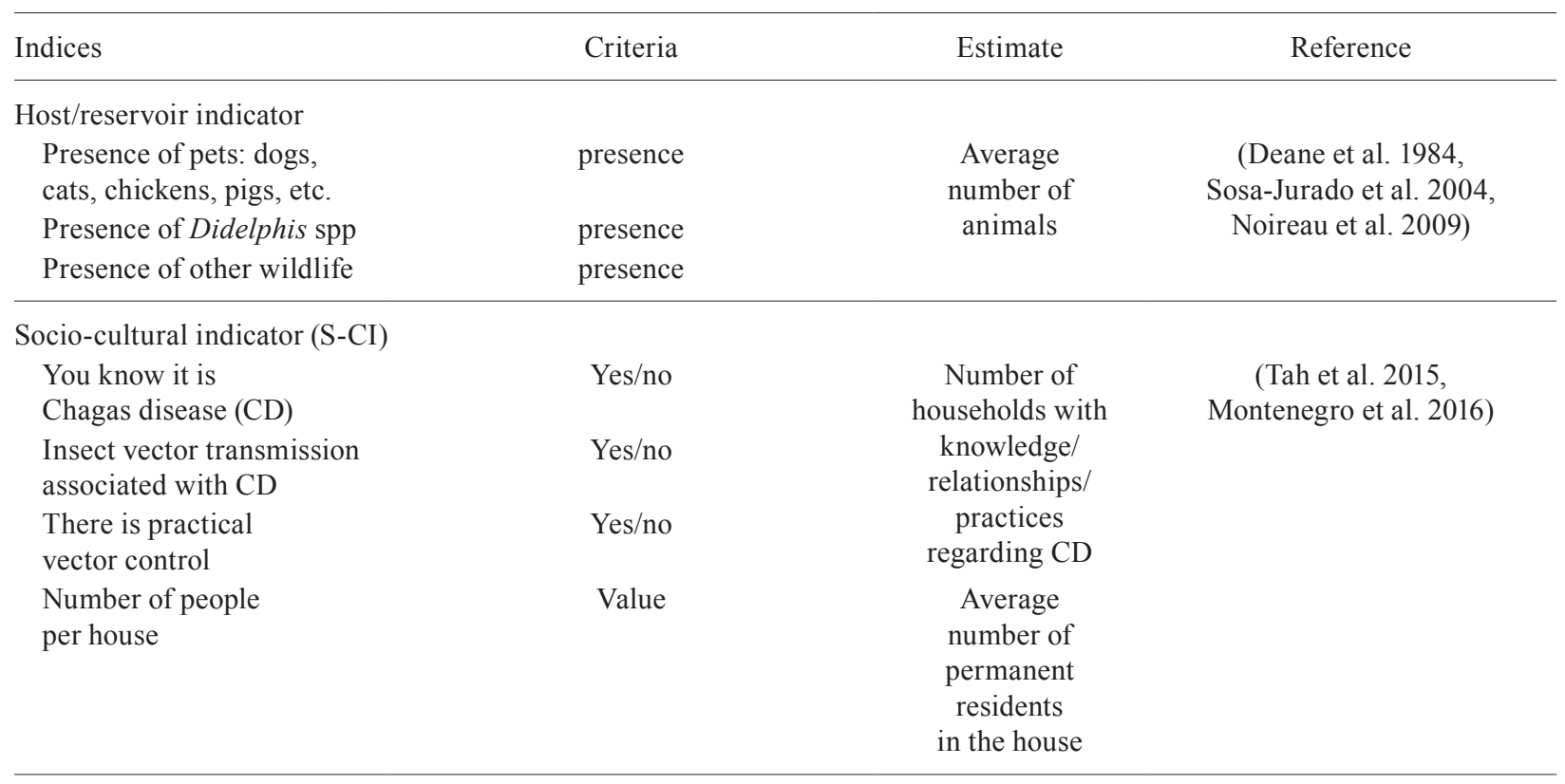

Houses with palm-leaf roofs or straw walls (bahareque and tapia), without plastering of the walls and with dirt floors were the most critical criteria selected in the HI. The presence of dogs and pigs, and the reports from residents of the presence of Didelphis spp., armadillos and mice had the highest contribution within $\mathrm{Ho} /$ RoI, while EI was dominated by the presence of rocks, stacked firewood and primarily palm trees in the peridomiciliar area. Distinguishing the pathology as CD and not applying vector control techniques within the S-CI, were the variables with the greatest absolute importance for intradomiciliar transmission of T. cruzi (Table II).

In the multi-criteria evaluation of the results of the PROMETHEE method, heterogeneous vulnerability scores were found for the 46 areas studied, and were normally distributed (standardised skewness and kurtosis of 1.49 and 0.75 , respectively). Based on the scores, $23.91 \%(11 / 46)$ of the territories are located in the lowest level of vulnerability (quartile 1), 50.00\% (23/46) in the intermediate level (quartile 2), and 26.09\% (12/46) in the highest level (quartiles 3 and 4) of vulnerability for the occurrence of CD vector-borne cases (Fig. 2).

Territories with the lowest values of vulnerability were Teislandia, San Pedro and Piedra Hancha, while those with the highest were Chaparral, El Bujio and Guayabal (Fig. 3). The most critical are affected by TI, EI and Ho/ RoI, and mainly triatomine indices, intradomiciliar perception of insects, natural infection with T. cruzi, and the presence of palm trees and domestic animals in peridomiciliar areas. On the other hand, the group with the lowest vulnerability is affected by S-CI, mainly the knowledge and practices of CD vector control (Fig. 3).

The LISA technique identified five villages (La Palma, Quebrada Honda, Santo Domingo, Une and Zulia) with significant spatial autocorrelation, and with it being negative only in Quebrada Honda (-0.0023; p =0.009) (data not shown).
On the other hand, the GAIA stick method found the TI, with a delta value of $80.07 \%$, followed by the HI, to be the most sensitive statistical vectors for categorising vulnerability of the territories assessed (Fig. 4).

\section{DISCUSSION}

The evidence provided by multi-criteria decision analysis using the PROMETHEE and GAIA methods and spatial statistics can establish scenarios of vulnerability to transmission of T. cruzi by different triatomine species in domiciliar environments, and facilitate approaches to combat them.

The PROMETHEE method, characterised as being prescriptive (Mareschal \& de Smet 2009), permitted the ranking of villages in order of priority for implementing actions to reduce the vulnerability of human populations to infection with T. cruzi. While the GAIA method, characterised as being descriptive and visual, allowed the discovery of the criteria (TI, HI and Ho/RoI) with the greatest contribution to vulnerability to $C D$ via vector through the "stick"-indicator (Fig. 2). The same method also allowed the identification of clusters of communities affected by common criteria (Fig. 2), as has been previously indicated (Hayez et al. 2009). For example, the greater the number of decision criteria used in the analysis, the GAIA method was statistically less robust, from having a Delta value of $80.14 \%$ (Fig. 2A), which is considered good (Hayez et al. 2009), to a Delta value of $44.64 \%$. The GAIA method also showed that some criteria, such as $\mathrm{S}-\mathrm{CI}$, lose their relevance in stratifying communities by levels of vulnerability (Fig. 2B). This technique works as a principal component analysis (Brans \& Mareschal 1994), and so can be useful for prioritising criteria with more or less statistical relevance in decision making.

The technique of spatial statistics, LISA, identified spatial dependence in the establishment of categories of 
TABLE II

Weights of the criteria for determining vulnerability for vector-borne transmission of Trypanosoma cruzi to humans

\begin{tabular}{|c|c|c|c|c|c|}
\hline Criterion & $\begin{array}{c}\text { Weight } \\
(\%)\end{array}$ & $\begin{array}{c}\text { Absolute } \\
\text { weight } \\
(\%)\end{array}$ & Criterion & $\begin{array}{c}\text { Weight } \\
(\%)\end{array}$ & $\begin{array}{c}\text { Absolute } \\
\text { weight } \\
(\%)\end{array}$ \\
\hline Triatomine indicator $(\mathrm{TI})$ & 44.96 & & Barn & 12.93 & 0.33 \\
\hline Triatomine secondary index & 19.88 & & Indicator of floor & 14.19 & \\
\hline Dispertion - Rhodnius prolixus (Rp) & 7.20 & 0.64 & Wooden floor & 22.95 & 0.76 \\
\hline Colonisation -Rp & 52.94 & 4.73 & Tiling & 8.72 & 0.29 \\
\hline Peridomiciliary infestion $-\mathrm{Rp}$ & 15.94 & 1.42 & Uncoated floor & 59.62 & 1.97 \\
\hline Intradomiciliary infestion $-\mathrm{Rp}$ & 23.92 & 2.14 & Cement & 8.72 & 0.29 \\
\hline Triatomine secondary index & 19.88 & & Host/reservoir indicator(Ho/RoI) & 12.32 & \\
\hline Dispertion - Panstrongilus geniculatus $(\mathrm{Pg})$ & 7.20 & 0.64 & Wild animals index & 16.95 & \\
\hline Colonisation -Pg & 52.94 & 4.73 & Primate & 14.93 & 0.31 \\
\hline Peridomiciliary infestion $-\mathrm{Pg}$ & 15.94 & 1.42 & Rat & 19.91 & 0.42 \\
\hline Intradomiciliary infestion -Pg & 23.92 & 2.14 & Mouse & 23.04 & 0.48 \\
\hline Index of perceptions of triatomines & 19.30 & & Bat & 18.89 & 0.39 \\
\hline Vector perception & 7.10 & 0.62 & Armadillo & 23.23 & 0.48 \\
\hline Palm tree & 12.19 & 1.06 & Index of opossum & 41.24 & \\
\hline Bush & 6.48 & 0.56 & Didelphis spp. & 100.00 & 5.08 \\
\hline Barn & 7.81 & 0.68 & Index of domestic animals & 41.81 & \\
\hline Henhouse & 12.06 & 1.05 & Equines & 16.61 & 0.86 \\
\hline Bird nests & 8.91 & 0.77 & Pig & 28.76 & 1.48 \\
\hline Stone & 8.82 & 0.77 & Chicken & 21.85 & 1.13 \\
\hline Firewood & 9.02 & 0.78 & Dog & 32.78 & 1.69 \\
\hline Bedroom & 19.95 & 1.73 & Ecotopes indicator $(\mathrm{EI})$ & 12.32 & \\
\hline Kitchen & 7.64 & 0.66 & Index of habitats & 33.33 & \\
\hline Index infection with $T$. cruzi & 40.94 & & Rock & 23.08 & 0.95 \\
\hline Trypanosoma spp. & 100.00 & 18.41 & Firewood & 23.08 & 0.95 \\
\hline House indicator(HI) & 23.26 & & Forest & 20.37 & 0.84 \\
\hline Index of roof & 31.50 & & Bush & 17.59 & 0.72 \\
\hline Thatch roof & 17.61 & 1.29 & Trees & 15.88 & 0.65 \\
\hline Eternit & 3.65 & 0.27 & Cane & 16.92 & 0.35 \\
\hline Clay tile & 13.39 & 0.98 & Coffee tree & 26.25 & 0.54 \\
\hline Zinc & 6.03 & 0.44 & Banana & 15.60 & 0.32 \\
\hline Palm tree leaves & 44.30 & 3.25 & Crop & 15.60 & 0.32 \\
\hline Wood roof & 15.03 & 1.10 & Grass & 25.64 & 0.53 \\
\hline Index of wall plaster & 23.62 & & Index of palm tree & 50.00 & \\
\hline Unplastered & 65.48 & 3.60 & Tertiary palm tree & 16.34 & 1.01 \\
\hline Partly plastered & 24.99 & 1.37 & Secondary palm tree & 29.70 & 1.83 \\
\hline Plastered & 9.53 & 0.52 & Primary palm tree & 53.96 & 3.32 \\
\hline Index of wall & 19.57 & & Socio-cultural indicator (S-CI) & 7.15 & \\
\hline Zinc & 4.54 & 0.21 & Index of control & 37.46 & \\
\hline Without wall & 22.98 & 1.05 & Unknown & 16.61 & 0.44 \\
\hline Wood & 11.35 & 0.52 & Yes & 11.52 & 0.31 \\
\hline Block or brick wall & 3.88 & 0.18 & Not & 71.87 & 1.92 \\
\hline Tapia & 20.40 & 0.93 & Index of knowledge of Chagas disease (CD) & 33.17 & \\
\hline Bahareque & 23.87 & 1.09 & Other diseases & 15.03 & 0.36 \\
\hline Adobe & 12.98 & 0.59 & Unknown & 8.51 & 0.20 \\
\hline Index of annexes & 11.12 & & $\mathrm{CD}$ & 49.74 & 1.18 \\
\hline Rustic bower & 13.32 & 0.34 & Yes & 26.72 & 0.63 \\
\hline Henhouse & 20.60 & 0.53 & Index of house investigated & 29.37 & \\
\hline Kitchen & 13.74 & 0.36 & Average number of persons per household & 66.67 & 1.40 \\
\hline Stable & 18.81 & 0.49 & Number of houses & 33.33 & 0.70 \\
\hline Pigsty & 20.60 & 0.53 & & & \\
\hline
\end{tabular}




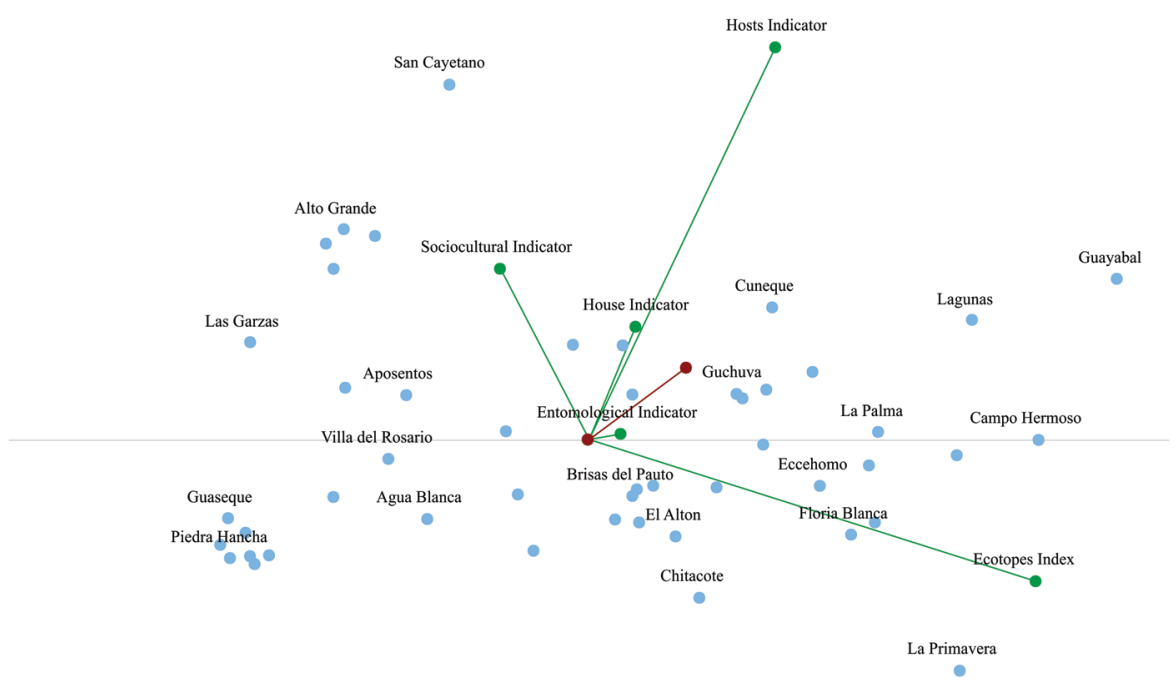

Delta: $44.65 \%$

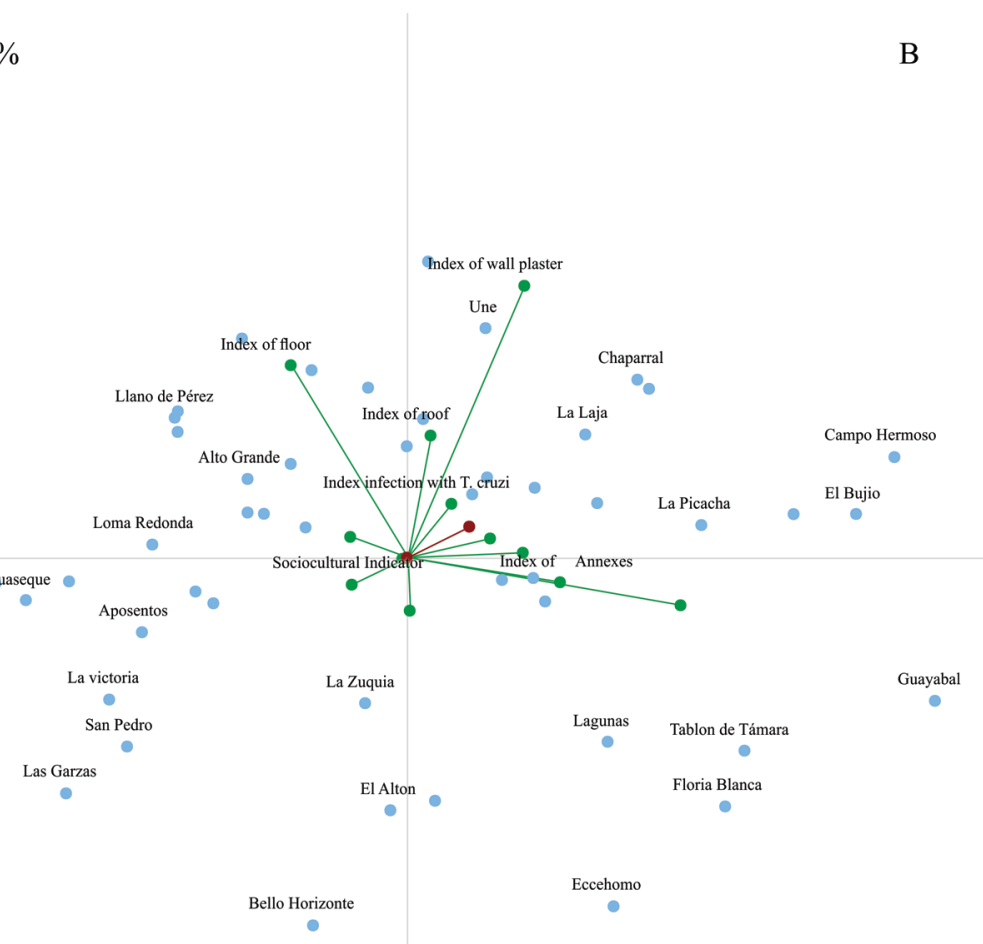

Fig. 2: display of the results of the multi-criteria preference ranking method for enrichment evaluation (PROMETHEE)-geometrical analysis for interactive assistance (GAIA) method for classification of intradomiciliar vulnerability to vector-borne Trypanosoma cruzi in an area endemic for Chagas disease. According to the indicator-house indicator (HI), triatominae indicator (TI), host/reservoir indicator (Ho/RoI), ecotope indicator (EI), socio-cultural indicator (S-CI) (B) and indicator and most relevant index of vulnerability (A).

vulnerability in five territories. Spatial analysis methods are useful for the creation or definition of homogeneous areas, the definition of indicators for monitoring and evaluation for a given intervention, and for setting priorities for planning and resource allocation. Therefore, the scenario of neighbor effect (border areas) on local values should also be incorporated in future studies for the establishment of vulnerability for CD.
This work is the first to evaluate the risk assessment questionnaire for Chagas disease in Colombia (Supplementary data) and according to the results, 37\% (77/210) of the criteria can be prioritised to categorise houses, villages, municipalities and departments within endemic regions of CD (Table II). However, depending on the ecoepidemiological scenarios in different endemic regions of $\mathrm{CD}$, some other criteria may need to be incorporated for stratification of areas of vulnerability for vector-borne CD. 

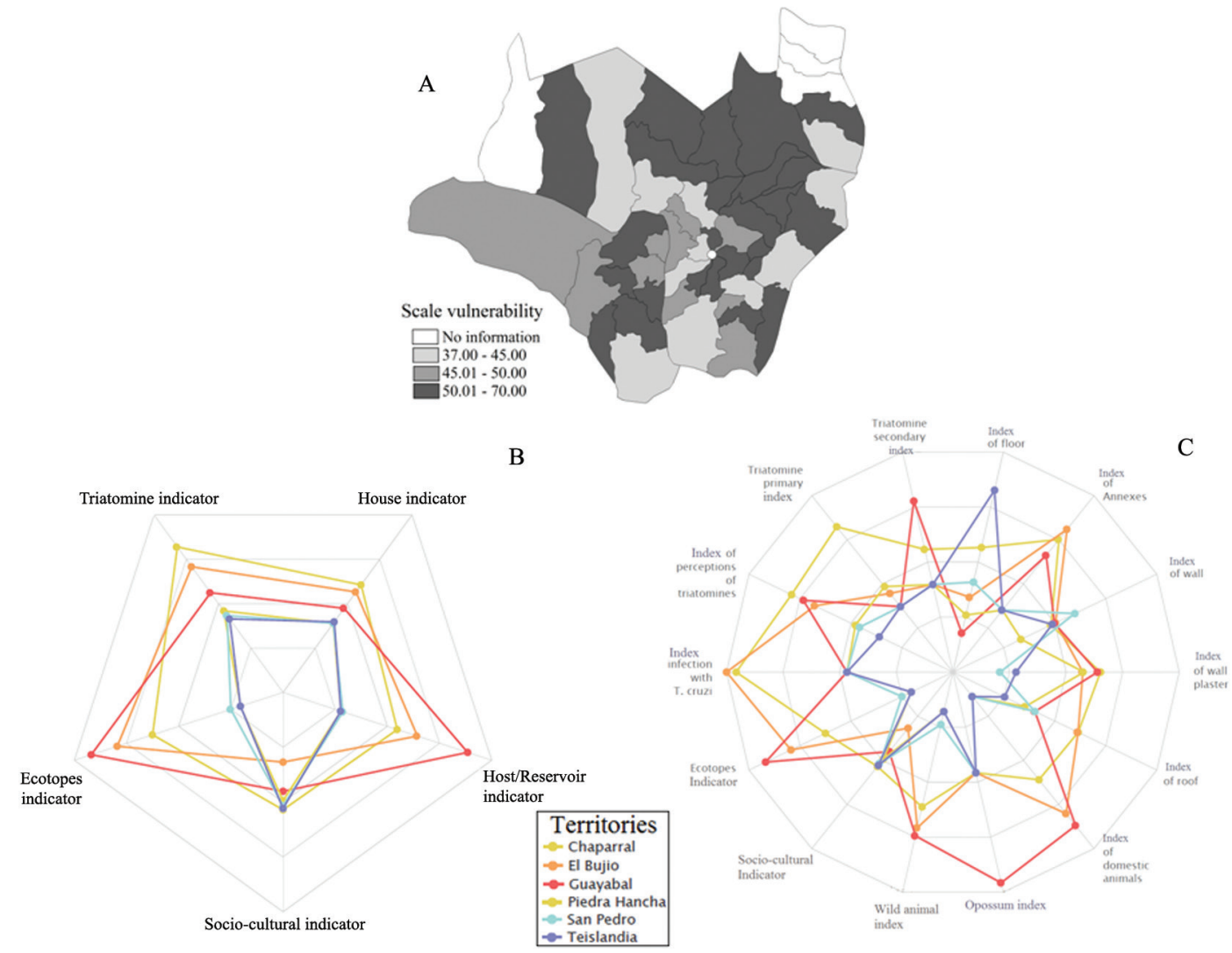

Fig. 3: ranking of the villages according to the preference ranking method for enrichment evaluation (Promethee) for estimating intradomiciliar vulnerability for vector-borne Trypanosoma cruzi (A). The three territories with the highest and lowest values of vulnerability based on the indicators house indicator (HI), triatominae indicator (TI), host/reservoir indicator (Ho/RoI), ecotope indicator (EI), socio-cultural indicator (S-CI) (B); the three territories with the highest and lowest values of vulnerability based on the indicators HI, TI, Ho/RoI, EI and S-CI and the most relevant indicators (C).
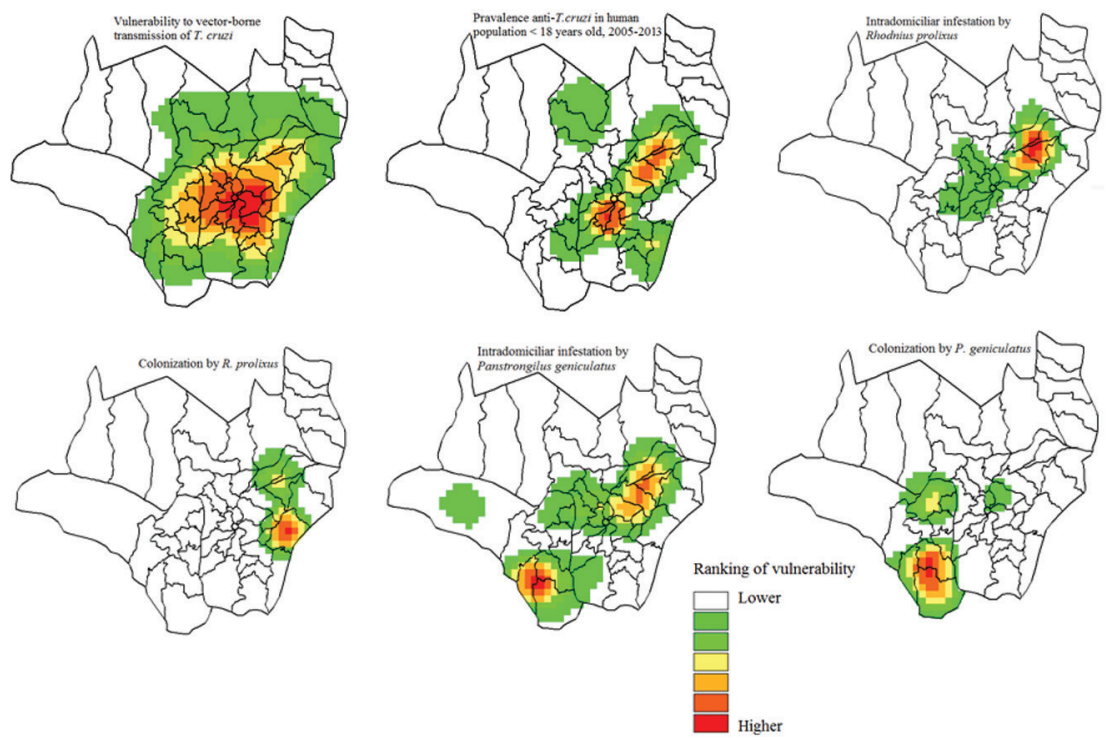

Fig. 4: panorama of human vulnerability to vector-borne Trypanosoma cruzi in an endemic area for Chagas disease, 2012-2013. 
The model for determining vulnerability presented here is a viable and other alternative to current models of risk (Guhl 2000, Silveira 2003) for several reasons.

This model does not include criteria or variables related to case detection or human infection with $T$. cruzi, which makes it more applicable in regular entomological CD surveillance actions because it can be applied from the residential level to any political-administrative division. Besides, the present work integrated spatial statistics to establish the effect of the neighboring areas in local vulnerability.

The different epidemiological importance of primary $(R$. prolixus), secondary $(P$. geniculatus) and tertiary (Rhodnius pictipes) vector species found in the study is related to their degree of synanthropy and the qualitative frequency of incrimination in $T$. cruzi transmission (Table I). This makes the TI flexible and can be adapted to different eco-epidemiological profiles in endemic areas, to the process of interruption and to targeting areas for serological surveillance.

The ideal is to determine which species of triatomine defecate $T$. cruzi metacyclic trypomastigotes, because this is the form infective to mammals (PerlowagoraSzumlewicz \& Moreira 1994). However, given the difficulty in differentiating the developmental stages of $T$. cruzi, Trypanosoma rangeli and Blastocrithidia triatomae within a vector (Junqueira et al. 2011), this study model simply used infection with Trypanosoma spp.

Recent classifications of triatomines of epidemiological importance, and relevant monitoring and control plans have been proposed (Abad-Franch 2016).

This study is the first to include the EI, which emphasizes palms. Palms function as an indicator of risk because they serves as habitat for the maintenance of triatomine populations that feed on mammals, birds and reptiles inhabiting the palm trees (Romaña et al. 1999, Noireau et al. 2009, Ricardo-Silva et al. 2012). In this case, we also separate palm trees into primary, secondary and tertiary, depending on the presence in the peridomiciliar area and records of infestation with triatomine. We emphasize the importance of determining rates of infestation with insects of the family Reduviidae (Table I). The presence of these ecotopes (palm trees) in peridomiciliar areas must be prioritised in the processes of interruption, because intradomiciliar infestation by wild populations from palm trees has been shown to occur even after intervention with chemicals (Feliciangeli et al. 2007).

The determinant S-CI, with overall weight of $7.15 \%$, is integrated into the vulnerability model for $\mathrm{CD}$ for the first time because it is very important as the pillar for sustaining community participation in the processes of regular entomological surveillance (Tah et al. 2015, Montenegro et al. 2016).

The model of the present study was shown to be predictive in areas where $\mathrm{CD}$ cases have historically occurred in the population under 18 years of age, as well as the association between intradomiciliar infestation of $R$. prolixus and $P$. geniculatus and the occurrence of $\mathrm{CD}$ cases (Fig. 4). This reinforces that, in addition to R. prolixus being the main vector of $T$. cruzi in Colombia, P. geniculatus is considered a secondary vector in country (MSPS/ INS 2011), and although it was not found to be infected with Trypanosoma spp., it may have an important role in the interruption process, as has already been indicated by (Montenegro et al. 2016). This hypothesis is reinforced by the similar values of vulnerability for $\mathrm{CD}$ produced by the PROMETHEE method for both species (Table II).

Finally, it is important to mention that the spatial statistical analyses were limited because the data were represented as polygons when data points or homes would have been better. However, this was not possible because at the time of the field survey it was not possible to georeference domiciles due to reasons of public order (presence of armed guerrilla groups).

For some trails it was not possible to work with $100 \%$ of the survey responses because some were not completed correctly or lacked relevant information.

Some samples of triatomines provided by community participation were discarded because their location of origin was unknown.

The ideal validation of the present vulnerability model would be by using information from serological screening of a human population for over five years in parallel with environmental and entomological study. Although these activities were carried out jointly, the results of the laboratory analyses were not obtained in a timely manner and/or this information no was accessed.

\section{ACKNOWLEDGEMENTS}

To the Health Secretary of Casanare, along with other national (MSPS/INS/PAHO-Colombia) and local (municipality of Támara) entities provided financial, technical, logistic and administrative support for the collection of information. Special thanks to Erik Wild, for revising the English grammar of this article.

\section{AUTHORS' CONTRIBUTION}

DM - contributed to the concept, design and application of MDA techniques and spatial statistic; APC and MP - contributed to the design and application of MDA techniques and spatial statistic; SL-A, AJV and MV - contributed to research project design and concept, data gathering and interpretation of results. All contributed to critically revising for important intellectual content, final approval of the version to be published, and all are agreement to be accountable for all aspects of the work in ensuring that questions related to the accuracy or integrity of any part of the work are appropriately investigated and resolved. The authors declare that we have prepared the manuscript in accordance with the standards of the journal, possess exclusive responsibility for the accuracy and correctness of the contents of the submitted article and declare that we have no conflicts of interest. The opinions expressed by authors contributing to this journal do not necessarily reflect the opinions of the journal or the institutions with which the authors are affiliated.

\section{REFERENCES}

Abad-Franch F, Ferraz G, Campos C, Palomeque FS, Grijalva MJ, Aguilar HM, et al. Modeling disease vector occurrence when detection is imperfect: infestation of Amazonian palm trees by triatomine bugs at three spatial scales. PLoS Negl Trop Dis. 2010; 4(3): e620.

Abad-Franch F. A simple, biologically sound, and potentially useful working classification of Chagas disease vectors. Mem Inst Oswaldo Cruz. 2016; 111(10): 649-51.

Anselin L. Local indicators of spatial association-LISA. Geogr Anal. 2010; 27(2): 93-115. 
Brans J-P, Mareschal B. The PROMCALC \&; GAIA decision support system for multicriteria decision aid. Decis Support Syst. 1994; 12(4-5): $297-310$

Catalá S, Crocco L, Morales G. Trypanosoma cruzi transmission risk index (TcTRI): an entomological indicator of Chagas disease vectorial transmission to humans. Acta Trop. 1997; 68(3): 285-95.

Chagas C. Nova tripanozomiaze humana. Estudos sobre a morfolojia e o ciclo evolutivo do Schizotrypanum cruzi n. gen., n. sp., ajente etiolojico de nova entidade morbida do homem. Mem Inst Oswaldo Cruz. 1909; 1(2): 159-228.

de Oliveira SV, Fonseca LX, Vilges KMA, Maniglia FVP, Pereira SVC, de Caldas EP, et al. Vulnerability of Brazilian municipalities to hantavirus infections based on multi-criteria decision analysis. Emerg Themes Epidemiol. 2015; 12(1): 15.

Deane MP, Lenzi HL, Jansen A, Deane MP, Lenzi HL, Jansen A. Trypanosoma cruzi: vertebrate and invertebrate cycles in the same mammal host, the opossum Didelphis marsupialis. Mem Inst Oswaldo Cruz. 1984; 79(4): 513-5.

Feliciangeli M, Sanchez-Martin D, Marrero M, Davies C, Jean-Pierre D. Morphometric evidence for a possible role of Rhodnius prolixus from palm trees in house re-infestation in the state of Barinas (Venezuela). Acta Trop. 2007; 101(2): 169-77.

Forattini OP. [Biogeography, origin and distribution of Triatominae domicile dispersal in Brazil]. Rev Saude Publica. 1980; 14(3): 265-99.

Guhl F, Restrepo M, Angulo VM, Antunes CMF, Campbell-Lendrum D, Davies CR. Lessons from a national survey of Chagas disease transmission risk in Colombia. Trends Parasitol. 2005; 21(6): 259-62.

Guhl F. Programas en la eliminación de la transmisión de la enfermedad de Chagas en Colombia. Academia Nacional de Medicina de Colombia. Medicina (B. Aires). 2000; 22(53): 96-105.

Hayez Q, de Smet, Bonney J. D-Sight: a new decision making software to address multi-criteria problems. Int J Decis Support Syst Technol. 2012; 4(4): 23 pp.

Hayez Q, Mareschal B, de Smet Y. New GAIA visualization methods. In: 13th International Conference Information Visualisation. 2009. Available from: http://ieeexplore.ieee.org/stamp/stamp. jsp?arnumber $=5190781$.

INPE - Instituto Nacional de Pesquisas Espaciais. TerraView. 2010. Available from: http://www.dpi.inpe.br/terraview/index.php.

Junqueira A, Gonçalves T, Moreira C. Manual de capacitação na detecção de Trypanosoma cruzi para microscopistas de malária e laboratoristas da rede pública. Rio de Janeiro: Fiocruz; 2011. 300 pp.

Lee BY, Bacon KM, Bottazzi ME, Hotez PJ. Global economic burden of Chagas disease: a computational simulation model. Lancet Infect Dis. 2013; 13(4): 342-8.

Mareschal B, de Smet Y. Visual PROMETHEE: developments of the PROMETHEE \& GAIA multicriteria decision aid methods. IEE. 2009; 1646-9.
Montenegro D, Vera M, Zuleta L, Llanos V, Junqueira A. Estrategia para determinar la línea base en áreas de interrupción vectorial de la enfermedad de Chagas. Rev Panam Salud Publica. 2016; 39(6): 341-51.

MSPS/INS - Ministerio de Salud y de la Protección Social/Instituto Nacional de Salud. Gestión para la vigilancia entomológica y control de la transmisión de la enfermedad de Chagas. Bogotá: MSPS; 2011.

Noireau F, Diosque P, Jansen AM. Trypanosoma cruzi: adaptation to its vectors and its hosts. Vet Res. 2009; 40(2): 26.

OPS - Organización Panamericana de la Salud. X Reunión de la comisión intergubernamental de la iniciativa Andina de control de la transmisión vectorial y transfusional de la enfermedad de Chagas - IPA - y VI Reunión de la iniciativa intergubernamental de vigilancia y prevención de la enfermedad de Chagas. Bogotá: 2011.

Perlowagora-Szumlewicz A, Moreira CJC. In vivo differentiation of Trypanosoma cruzi 1 - 1. Experimental evidence of the influence of vector species on metacyclogenesis. Mem Inst Oswaldo Cruz. 1994; 89(4): 603-18.

Rabinovich JE, Leal JA, de Piñero DF. Domiciliary biting frequency and blood ingestion of the chagas's disease vector Rhodnius prolixus ståhl (Hemiptera: Reduviidae), in venezuela. Trans R Soc Trop Med Hyg. 1979; 73(3): 272-83.

Ricardo-Silva AH, Lopes CM, Ramos LB, Marques WA, Mello CB, Duarte R, et al. Correlation between populations of Rhodnius and presence of palm trees as risk factors for the emergence of Chagas disease in Amazon Region, Brazil. Acta Trop. 2012; 123(3): 217-23.

Romaña CA, Pizarro JC, Rodas EEG. Palm trees as ecological indicators of risk areas for Chagas disease. Trans R Soc Trop Med Hyg. 1999; 93(6): 594-5.

Silveira A. Modelos factibles de vigilancia de la enfermedad de Chagas. Rev Patol Trop. 2003; 32(2): 175-84.

Silveira AC, de Rezende DF, Máximo MHC. Risk measure of domestic transmission of Chagas' disease, through a new entomological indicator. Mem Inst Oswaldo Cruz. 1984; 79(Suppl.): 113-5.

Sosa-Jurado F, Zumaquero-Ríos JL, Reyes PA, Cruz-García A, Guzmán-Bracho C, Monteón VM. Factores bióticos y abióticos que determinan la seroprevalencia de anticuerpos contra Trypanosoma Cruzi en el municipio de Palmar de Bravo, Puebla, México. Salud Publica Mex. 2004; 46(1): 39-48.

Tah ARV, Gómez LH, Beutelspacher AN, Canto JO, Ramsey JM. La vulnerabilidad humana a la transmisión vectorial de Trypanosoma cruzi a través de los procesos de salud-enfermedad y la apropiación social del territorio. Salud Colect. 2015; 11(2): 191-210.

Vega M. Informe final del evento enfermedad de Chagas. Bogotá: 2014.

Vinhaes MC, de Oliveira SV, Reis PO, Sousa ACL, Silva RA, Obara MT, et al. Assessing the vulnerability of Brazilian municipalities to the vectorial transmission of Trypanosoma cruzi using multicriteria decision analysis. Acta Trop. 2014; 137(2): 105-10.

WHO - World Health Organization. Investing to overcome the global impact of neglected tropical diseases. Third WHO report on neglected tropical diseases. Geneva: 2015. 